\title{
Cultural and Gender Differences in Gender-Role Beliefs, Sharing Household Task and Child-Care Responsibilities, and Well-Being Among Immigrants and Majority Members in The Netherlands
}

Judit Arends-Tóth • Fons J. R. van de Vijver

Published online: 13 June 2008

(C) Springer Science + Business Media, LLC 2008

\section{Erratum to: Sex Roles}

DOI 10.1007/s11199-007-9316-Z

In "Cultural and Gender Differences in Gender-Role Beliefs, Sharing Household Task and Child-Care Responsibilities, and Well-Being Among Immigrants and Majority Members in The Netherlands" (Volume 57, Numbers 11/12, December 2007, pp. 813-824, DOI 10.1007/s11199-007-9316-z) the authors' names and their affiliations were erroneously stated. The authors' names should have appeared as above, and the authors' affiliations are as seen below.

Springer regrets the errors.

The online version of the original article can be found at doi: http:// 10.1007/s11199-007-9316-Z

J. Arends-Tóth

Department of Psychology, Tilburg University,

P.O. Box 90153, 5000 LE Tilburg, The Netherlands

e-mail: judit.arends@planet.nl

F. J. R. van de Vijver $(\bowtie)$

Tilburg University,

Tilburg, The Netherlands

e-mail: fons.vandevijver@uvt.nl

F. J. R. van de Vijver

North-West University,

Mmabatho, North West, South Africa 